\title{
Sterilization of Oil Palm Fresh Fruit Using Microwave Technique
}

\author{
I. Umudee, M. Chongcheawchamnan, M. Kiatweerasakul, and C. Tongurai
}

\begin{abstract}
Dramatically increasing rate of free fatty acid (FFA) in long storage oil palm fruit is one of the most crucial problems of oil palm mill industries. The aim of this paper is to study the possibility of oil palm fruits sterilization by using microwave irradiation in order of halting enzymatic lipolysis reaction which caused of FFA production. The results indicate that microwave heating can be interrupted the FFA produced reaction and the optimum condition heating temperature of the fruits mesocarp is $50{ }^{\circ} \mathrm{C}$ but not exceed to $80^{\circ} \mathrm{C}$, and the fruits can be storage for 7 days at ambient condition without FFA significantly generation. Conclude that heating from irradiation of microwave is capacitating for dry and clean sterilization system.
\end{abstract}

Index Terms - Sterilization, palm fruit, microwave, free fatty acid.

\section{INTRODUCTION}

High content of free fatty acid (FFA) in crude palm oil is one of the most crucial problems for most of the palm oil mill. After harvesting, oil palm fruit needs to be extracted early as possible before the high rate increasing of FFA will be occurred. However, the limitation on the number of oil palm extracting plants does not adequate to oil palm production, protracted storage and rapidly increasing of FFA of the fruit is unavoidable.

Sterilization has been required as a primary stage in extracting process in order to fecilely detach and destruct enzymes, the cause of production of free fatty acid. Afterwards, the bunches consist of oily and soft fruit were threshed by rotary beater to remove the fruit from the bunch before extracting by screw pressing.

At the present, large- and medium-scale palm oil mills were used a steam sterilization process which has pressurized the bunches of 15-45 psi for $90 \mathrm{~min}$ at a temperature more than $100{ }^{\circ} \mathrm{C}$ [1] and [2]. Palm oil from this process has good quality. Neverthless, effectively steam sterilization process has produced many waste water because of the large amount of water used in the process. Thus the high cost of discharge treatment was necessary to rigorous environmental standard.

Most small-scale processors do not have more ability to generate steam for sterilization. Therefore, non-steamed sterilization of the bunch such as cooking and drying are alternative process [3]. But disadvantage of this process is getting lower quality of crude palm oil due to excessive

Manuscript received February 11, 2013; revised April 17, 2013.

The authors are with the Department of Chemical Engineering, Faculty of Engineering, Prince of Songkla University, Songkhla 90112 Thailand (e-mail: ilhamfitree@gmail.com, mitchai@coe.psu.ac.th, montep.k@psu.ac.th, chakrit.t@ psu.ac.th). temperature operation. Very low moisture content of the fruit during drying performance, hardened mesocarps make the depericarping operations difficult, and maintenance cost augmentation is inevitable [4]. Effectiveness non-steam sterilization technique has been appropriated.

Microwave energy is being developed as a new tool for high temperature process which is rapid and uniform heating including decrease sintering temperatures. Heating carried out by microwave is the result of microwave energy by a material exposed to the electromagnetic field [5]. Dipolar substance, especially water, the main ingredient in the oil palm fruit, can be thoroughly heated by dielectric heating of microwave irradiation [6].

In order of palm fruit detachment from the bunch, the microwave technique is very effective. By reason of high dielectric properties of abscission region that could be an electric field absorb, therefore, abscission region will heat up and perform fruit loosening from the bunch effortlessly [7].

The concentration of vitamin $\mathrm{E}$ and carotenes in the microwave heating oil extracted were higher than steam sterilization oil extracted due to lower temperature used [8].

The aim of this research is monitoring the feasibility of the beneficence of microwave heating as a primary stage of the milling process for enzymatic denatured which could be reduce increasing rate of FFA, extensively store will not be more decisive problem of milling process.

\section{EXPERIMENTAL PROCEDURE}

\section{A. Microwave Oven}

The compact oven LG MS-1822C, 2,450 MHz, 800 watts which has dimensions of $455 \mathrm{~mm} \times 281 \mathrm{~mm} \times 313 \mathrm{~mm}$ with $240 \mathrm{~mm}$ turn-table diameters for all experiments.

\section{B. Processing of Oil Palm Fresh Fruitlet}

The un-bruised oil palm fresh fruit bunches were collected from Klong Hoi Khong Research Station palm oil plant, Faculty of Natural resources, Prince of Songkla University. All experiments were conducted on the same day as the bunch were harvested. The experiments were carried out on $500 \mathrm{~g}$ of fruitlet which is detached by slight push of the finger from the apical and equatorial portion of the bunch (Fig. 1a.).

The color of the fruit was specified to mostly orange which has the most of oil content in the mesocarp [9]. The samples were heated in the microwave oven at 90 and $360 \mathrm{~W}$ for 10 and $15 \mathrm{~min}$.

\section{Processing of Oil Palm Fresh Spikelet}

A whole bunch was chopped into spikelets, collected from apical and equatorial zone only. Equalize placed the $1 \mathrm{~kg}$ of 
spikelets on a turn-table plate, then heated in the microwave oven at 90 and $360 \mathrm{~W}$ for 20,30 and $40 \mathrm{~min}$ respectively. The heated fruit was detached from the outer fruit of the spikelet for FFA analysis (Fig. 1b.).

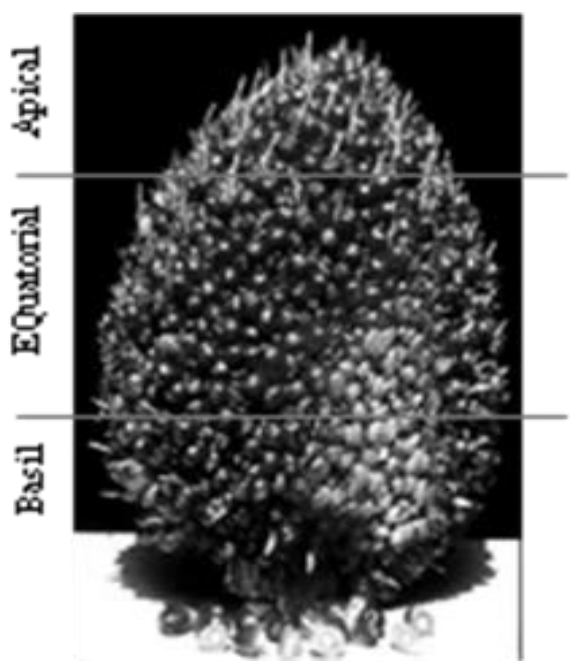

(a)

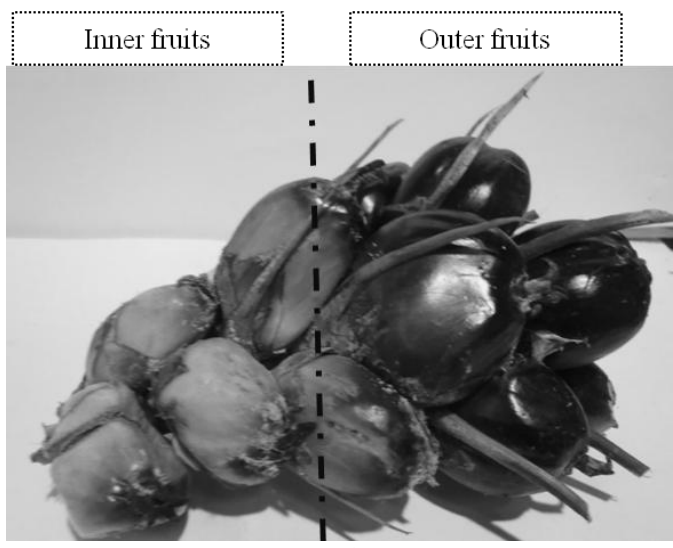

(b)

Fig. 1. (a) Schematic division of fruit bunch. (b) The outer and inner halves of a spikelet [9].

The temperature of the heated fruit was determined immediately for all experiments, the FFA content of extracting heat oil palm fruit and non-heated fruit, placed in dry condition, left the samples for 7 days and analysed over day 3,5 and 7 .

\section{Free Fatty Acid Content of Palm Oil Analyses}

The FFA content of extracting oil palm was analysed according to AOCS Official Method with isopropanol used as a solvent [10].

TABLE I: EFFECT OF MicRowAVE HEATING POWER LEVEL AND DURATION TIME OF MESOCARP TEMPERATURE OF OIL PALM FRUITLET

\begin{tabular}{lll}
\multirow{2}{*}{$\begin{array}{c}\text { Heating time } \\
\text { (min) }\end{array}$} & \multicolumn{2}{c}{ Temperature of mesocarp $\left({ }^{\circ} \mathrm{C}\right)$} \\
\cline { 2 - 3 } 10 & $90 \mathrm{~W}$ & $360 \mathrm{~W}$ \\
\hline 15 & 44 & 77 \\
& 48 & 82 \\
\hline \hline
\end{tabular}

TABLE II: EFFECT OF MiCROWAVE HEATING POWER LEVEL AND TIME ON MESOCARP TEMPERATURE OF OIL PALM FRUITLET

\begin{tabular}{lll}
\hline \hline \multirow{2}{*}{$\begin{array}{c}\text { Heating time } \\
(\text { min })\end{array}$} & \multicolumn{2}{c}{ Temperature of mesocarp $\left({ }^{\circ} \mathrm{C}\right)$} \\
\cline { 2 - 3 } 20 & $90 \mathrm{~W}$ & $360 \mathrm{~W}$ \\
\hline 40 & 43 & 57 \\
& 51 & 61 \\
\hline \hline
\end{tabular}

\section{RESULTS AND DisCUSSION}

\section{A. Sterilization of Oil Palm Fresh Fruitlet}

The temperature of microwave heating oil palm fruit mesocarp was shown in Table I and II, the results indicated that increasing of the mesocarp temperature of the fruit is directly proportion to microwave power and heating duration. It is to be noted that at low microwave power, the temperature of an equal microwave power different heating time does not very significant, elucidate the limitation of comprehension of microwave energy irradiation at shorting time.

For spikelet microwave heating, the fruit thus embedded in a spikelet which has highly dielectric constant that indicated to microwave absorption capability of empty spikelet, caused of energy loss, long operating time is necessary.

Fig. 2 shows the percentage increments of FFA of oil palm fruitlet that was carried out by 90 Watt microwave-heated oil palm fruit compared between heating duration for 10,15 minutes and non-heating sample. The results indicated that at temperature less than $50{ }^{\circ} \mathrm{C}$, FFA is continuously increasing.

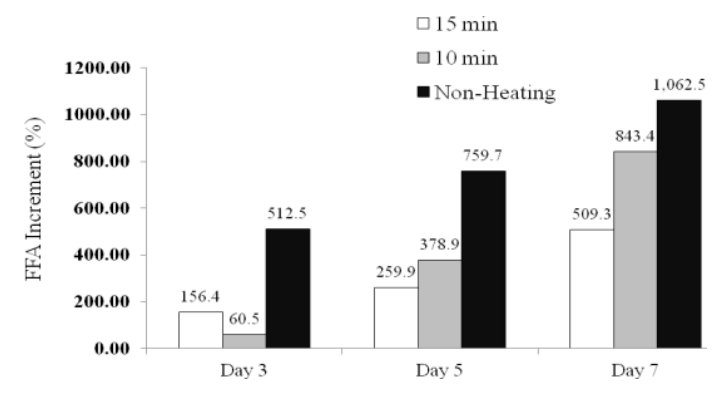

Fig. 2. The percentage increments of FFA content at $90 \mathrm{~W}$ microwave-heated of oil palm fruitlet.

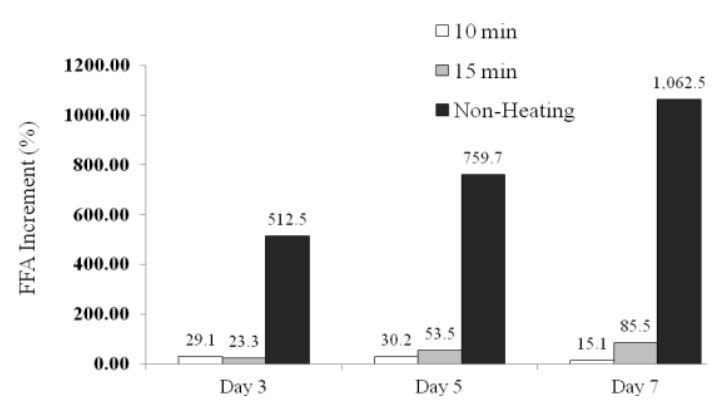

Fig. 3. The percentage increments of FFA content at $360 \mathrm{~W}$ microwave-heated of oil palm fruitlet.

But consider on non-heating fruitlet which has more increasing rate than heated fruit, the significant differential attests that microwave heating can be halted enzymatic reaction. 
Suitable condition for microwave heating of the oil palm fruitlet was shown in Fig. 3, indicated that low increment rate of FFA of heating fruit. However, long heating duration has damage fruit's mesocape to be bruised, may cause of moisture adsorption, hydrolysis reaction will be occurring and FFA is increased when the storage of heated fruit not conveniently.

From the result, properly heating temperature is not over than $80{ }^{\circ} \mathrm{C}$ is appropriate for FFA raising rate control.

\section{B. Sterilization of Oil Palm Spikelet}

Fig. 4 shows the percentage increments of FFA content when supply microwave-heating for 90 Watt various heating times. The result indicated heating spikelet could be more control FFA increasing than non-heating sample.

Heating time for $40 \mathrm{~min}$ has most effective for FFA increasing control.

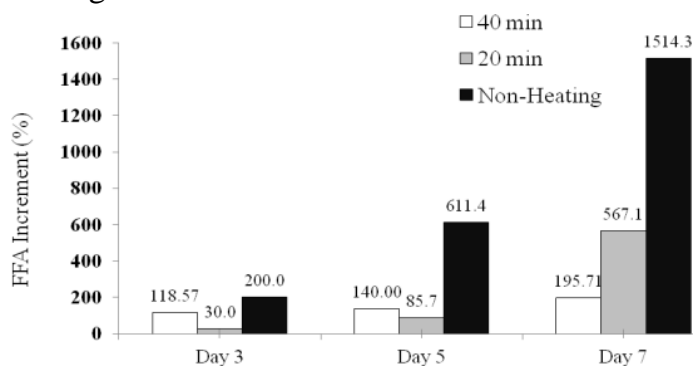

Fig. 4. The percentage increments of FFA content at $90 \mathrm{~W}$ microwave-heated

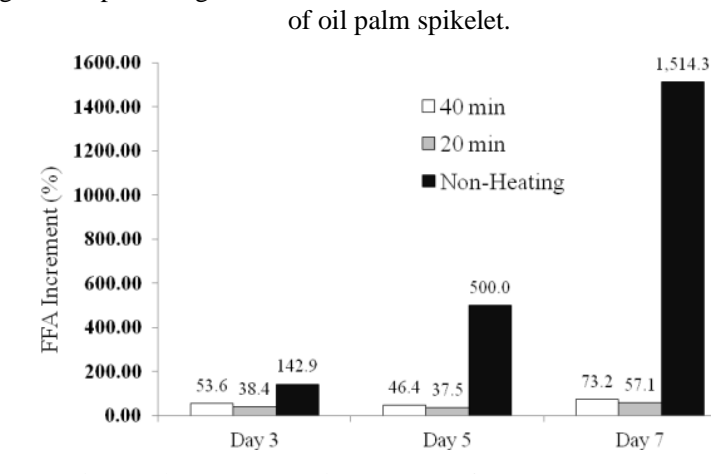

Fig. 5. The percentage increments of FFA content at $360 \mathrm{~W}$ microwave-heated of oil palm spikelet.

Fig. 5. shows the results of $360 \mathrm{~W}$ microwave power heating under various duration. No significantly increasing of FFA was observed after irradiation of microwave both for 20 and $40 \mathrm{~min}$. On the other hands, higher rate increasing of FFA were observed in non-heating samples.

As a result of FFA generation mentioned above, microwave radiation palm oil fruit could be retained 7 days, advantages for pressing tarried fresh oil palm fruits. It can be seen that the microwave sterilization system is suggested to have effectively and conveniently to enzyme inactivation in palm oil fresh fruits.

\section{ACKNOWLEDGMENT}

The authors gratefully acknowledge the financial support from the Graduate School of the Prince of Songkla University (PSU), Hat Yai. The technical contents presented are supported by the Specialized R\&D Center for Alternative Energy from Palm Oil and Oil Crops, as well as from the PSU Department of Chemical Engineering, and are also deeply appreciated.

\section{REFERENCES}

[1] K. Sivasothy, "Palm oil milling technology," Advances in Palm Oil research," vol. 1, pp. 745-775, 2000

[2] M. C. Chow and A. N. Ma, "Processing of fresh palm fruits using microwaves," Microwave Power Electromagnetic Energy, vol. 40, no. 3, pp. 165-173, April, 2007.

[3] K. Poku, Small-Scale Palm Oil Processing in Africa, FAO, Rome: FAO Agriciltural services bulletin, ch. 3, pp. 11-12. 2002

[4] N. A. Hadi, N. M. Han, C. Y. May, and M. A. Ngan, "Drying heating of palm fruits: effect on selected parameters," AJEAS Trans. on Science Publications., vol. 5, no. 2, pp. 128-131, Aug. 2012.

[5] D. E. Clark, D. C. Folz, and J. K. West, "Processing materials with microwave energy," Materials Science and Engineering: A, vol. 287, no. 2, pp. 153-158, Aug. 2000.

[6] S. Iwaguch, K. Matsumura, Y. Tokuoka, S. Wakui, and N. Kawashima, "Sterilization system using microwave and UV light," Colloids and Surfaces B: Biointerfaces, vol. 25, no. 4, pp. 299-304, Aug. 2002.

[7] N. Sukaribin and K. Khalid, "Effectiveness of sterilization of oil palm bunch using microwave technology," Industrial Crops and Products, vol. 30, no. 2, pp. 179-183, Sep. 2009.

[8] S. F. Cheng, L. Mohd Nor, and C. H. Chuah, "Microwave pretreatment: A clean and dry method for palm oil production," Industrial Crops and Products, vol. 34, no. 1, pp. 967-971, April 2011.

[9] Z. Abbas, "A microstrip sensor for determination of harvesting time for oil palm fruits," M. S. thesis, Environ. Sc., Putra Univ., Selangor, Malaysia. 1994

[10] AOCS Official Method Ca 5a-40: Free fatty acids, American Oil Chemists' Society, Boulder, Urbana, 2009.

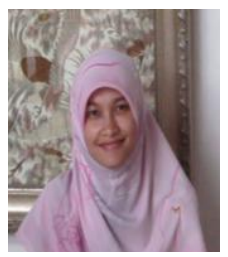

I. Umudee was born in Narathiwat, Thailand, in 1985. She received the B.Eng. degree in Chemical Engineering from Prince of Songkla University, Songkhla, Thailand, in 2008. Her current research interest is microwave techniques for agricultural applications.

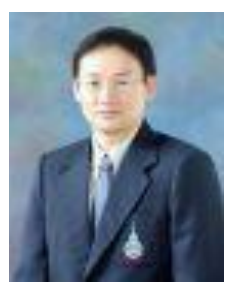

M. Chongcheawchamnan was born in Bangkok, Thailand, in 1970. He received the B.Eng. degree in telecommunication from King Mongkut's Institute of Technology Ladkrabang, Bangkok, in 1992, the M.Sc. degree in communication and signal processing from Imperial College, London, U.K., in 1995, and the $\mathrm{Ph} . \mathrm{D}$. degree in electrical engineering from the University of Surrey, Guildford, U.K., in 2001.

$\mathrm{He}$ joined the Mahanakorn University of Technology, Bangkok, in 1992, as a Lecturer. In 2008, he joined the Faculty of Engineering, Prince of Songkla University, Songkhla, Thailand, as an Associate Professor. His current research interests include microwave circuit design and microwave techniques for agricultural applications. Dr. Chongcheawchamnan is a member of the IEEE Microwave Society.

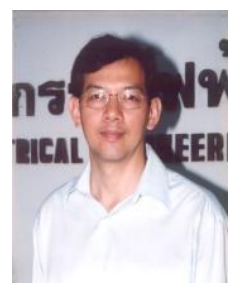

M. Kiatweerasakul was born in Bangkok, Thailand, in 1962. He received B.Sc. and M.E. degrees in Electrical Engineering from Prince of Songkla University, Thailand in 1985 and 1991, respectively, the M.Phil. degree in Electronic and Electrical Engineering from the University of Leeds, UK, in 2000, the Ph.D. degree in Electronic and Computer Engineering from Brunel University, UK, in 2004.

Since April 1985, he has been a lecturer at the Department of Electrical Engineering, Prince of Songkla University. His interests include RF and microwave system design, RFID, electronic measurement instrument, and microcontroller applications.

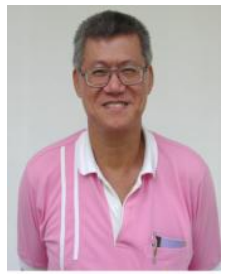

C. Tongurai was born in Prachuapkhirikhan, Thailand, in 1955. He received the B.Sc. degree from Chulalongkorn University, Thailand, the D.E.A. degree in chemical engineering from Institute of Chemical Engineering, Toulouse, France, and the D.Ing. in chemical engineering from Institute of Chemical Engineering, Toulouse, France.

$\mathrm{He}$ joined the Faculty of Engineering, Prince of Songkla University, Songkhla, Thailand, as an Associate Professor. His current research interest is biodiesel. 